\title{
The Effect of Labor Mobility on the Urban-Rural Income Gap-Based on 272 Prefecture-Level City Panel Data in China
}

\author{
Han Li \\ Jinan University, Guangzhou, China \\ Email: ltz1330@163.com
}

How to cite this paper: Li, H. (2018) The Effect of Labor Mobility on the Urban-Rural Income Gap-Based on 272 Prefecture-Level City Panel Data in China. Modern Economy, 9, 1287-1300.

https://doi.org/10.4236/me.2018.97083

Received: July 3, 2018

Accepted: July 23, 2018

Published: July 26, 2018

Copyright $\odot 2018$ by author and Scientific Research Publishing Inc. This work is licensed under the Creative Commons Attribution International License (CC BY 4.0).

http://creativecommons.org/licenses/by/4.0/

\begin{abstract}
The current income gap situation between urban and rural areas is still one of the important problems on the road of China's economic development; based on the panel data of 272 prefecture-level cities in China from 2003 to 2012 and the theory of labor mobility, this paper uses the quantile regression and OLS regression to study the relationship between labor mobility and urban-rural income gap. The empirical results show that: labor mobility can effectively narrow the income gap between urban and rural areas, and with the increase in the number of quantile points, this reduction effect increases. The impact of industrial structure and industrialization level has changed at different quantile points, but the investment in science and education, the scale of financial development, and the impact of social security have not changed.
\end{abstract}

\section{Keywords}

Urban-Rural Income Gap, Labor Mobility, Quantile Regression

\section{Introduction}

With the gradual promotion and implementation of the household contract responsibility system and the market economy system during the reform and opening, rural productivity has rapidly recovered and China's economy has undergone rapid changes. In the process of urbanization and industrialization, especially the rapid development of economic and trade in the eastern coastal areas attracted a large number of rural laborers to migrate to cities. In the 1980s, an upsurge of migrant workers entering the city was formed. The 2016 Migrant Workers Monitoring Survey Report showed that although the growth rate of total migrant workers from 2011 to 2016 has been declining, it has reached a huge scale of 280 million in 2016. From the perspective of the absolute difference in 
income gap, the absolute income gap between urban and rural areas in 2016 was 21,253 yuan. If the base period was 1978 whose income gap was 209.8 yuan, the urban-rural income gap in 2016 was 101.3 times that of 1978. In recent years, as China's economy has entered a new normal, in order to reduce the urban-rural income gap while maintaining stable economic growth, the economic achievements should be better distributed among various members of society, becoming a topic of our concern. At the G20 Summit in 2016, Chairman Xi Jinping pointed out that the global Gini coefficient has reached 0.7 , exceeding the international risk line of 0.6 , and the income gap has become the focus of the world's attention.

As a typical dual economic structure country, China's rural surplus labor force has been transferred from rural areas to cities, which is an inevitable process of economic development and social progress. At present, domestic and foreign scholars' research on labor mobility and urban-rural income gap mostly adopts provincial-level data, and this paper uses panel data of 272 prefecture-level cities, which will help to further reveal the specific impact of labor mobility on urban-rural income gap. This paper carefully understands and grasps the problems of urban-rural income gap in the process of China's industrialization, industrial structure upgrading, and financial development during the period of market economy transition period. From the perspective of labor mobility, we will thoroughly analyze the role and impact of rural labor mobility on the income gap between urban and rural areas in China, explore the deep-seated mechanism of this pattern, and distinguish the market's own defects from institutional factors in this profit distribution mechanism and reveal the formation of government policies so that put forward useful suggestions. But 15 cities were severely deleted due to missing data, and this is the shortcoming of this article.

The article is organized as follow:

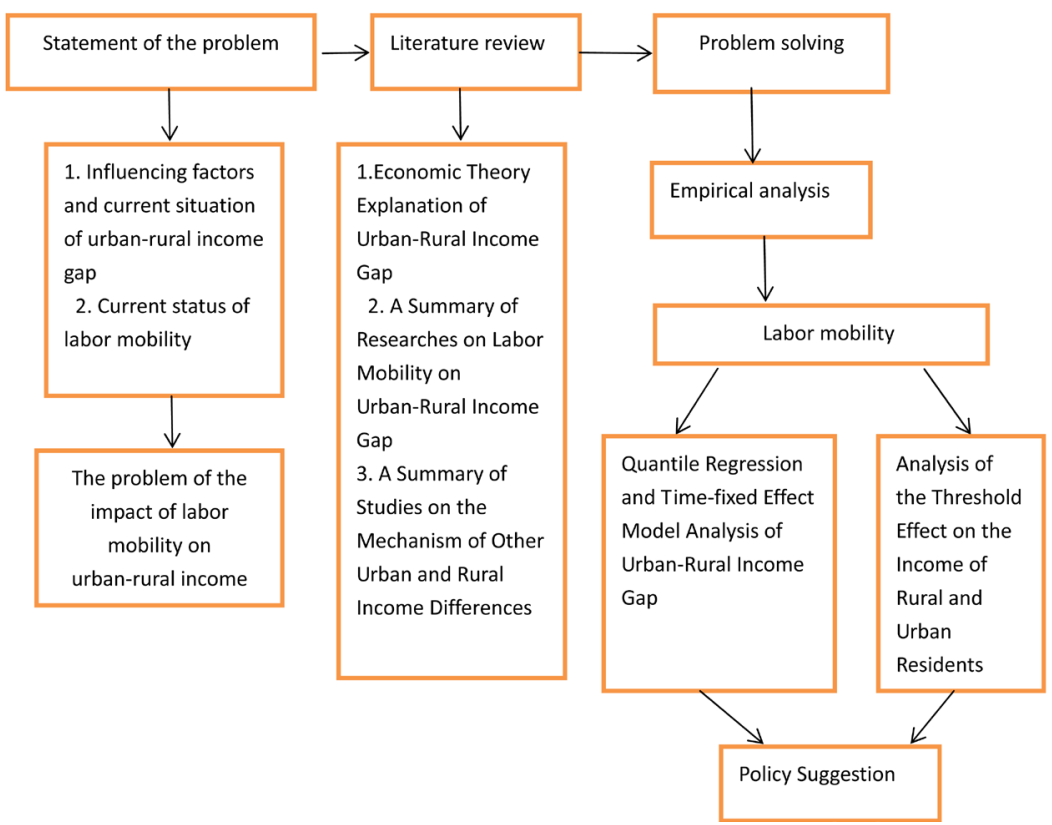




\section{Literature Review}

Todaro's "expected income" theory believes that people aim at maximizing expected income, and compare the actual urban-rural income gap and the probability of finding a job in the city with the expected income difference, so as to make a flow decision. Stark's "relative poverty hypothesis" believes that the more unequal the income distribution between households, the greater the sense of poverty among people. In order to eliminate poverty, many families who feel that their economic status is declining will have a motive for migration. Domestic and foreign scholars mainly hold two views on the relationship between the labor mobility and the urban-rural income gap, some scholars believe that the flow of labor expands the income gap between urban and rural areas, however Some scholars believe that the flow of labor reduces the income gap between urban and rural areas.

\subsection{Representative Research Literature That Labor Mobility Expands the Income Gap between Urban and Rural Areas}

Justin, Gewei Wang [1] studied the labor mobility and income gap between urban and rural areas in China during 1985-1990 and 1995-2000. The results show that during the period 1985-2000, with the expansion of the labor force, the income gap between urban and rural areas has also expanded, that is, the positive relationship between the two. Chan, Buckingham [2], Zhang Yuan, Wang Hao [3], Yu Xianghua, Chen Xuejuan [4]; Zhang Li, Li Shi [5] pointed out that China's unique household registration system has seriously hindered the migration of labor force. Because the existence of the "agriculture household to non-agricultural household" approach has created more obstacles for labor transfer, it has been unable to reduce the income gap between urban and rural areas. Fan Shide [6] based on the theoretical derivation of the mechanism of the labor mobility's effect on the urban-rural income gap and empirical analysis which use the relevant data. He believes that due to the Non-Market free movement of China's labor force and the exclusion and discrimination of Non-local workers in developed regions, the meager income earned by labor mobility cannot narrow the income gap between urban and rural areas. Zhai Yuanfeng, Zhan Wanming [7] and Cai $\mathrm{Wu}$, Chen Guanghan [8] expand the heterogeneity structure of the floating labor force to the traditional human capital spillover theory, analyzing the impact mechanism of urban-rural human capital spillovers and labor mobility on the urban-rural income gap. The transfer costs and merit shifts of the rural labor force will endogenously lead to an increase in the urban-rural income gap in China. Cai Wu, Wu Guobing, and Zhu Xiu [9] introduced the agglomeration of spatial externality according to the theory of new economic geography and found that the agglomeration scale index and the coordinator of the spatial output density and the labor rate flow are both positive influence, the movement of rural labor in China has accelerated the urban-rural income gap by accelerating urban industrial agglomeration. From the perspective of space, 
Zheng Jianghuai, Gao Yanyan [10], Chen Jianjun [11] believe that industrial shifts have changed the spatial choice of labor mobility, mainly by trans-regional transfer to the local. And in the process of urban industrial agglomeration, the impact of rural labor mobility on the income of urban and rural residents in China is still in a phase of polarization effect, which will further widen the urban-rural income gap (Cai Wu, Chen Wangyuan, [12], Liu Jun, Wang Jiaxuan, Yang Haochang [13]). On the other hand, some urban biased policies have resulted in discrimination against the transfer of labor in rural areas, which has reduced the economic efficiency. Due to the long-term implementation of the "urban bias" fiscal allocation mechanism, fiscal expenditure has significantly expanded the income gap between urban and rural areas (Deng Xuan [14], Ge Lei, Tao Xiaoma, Wang Hong [15]).

\subsection{Representative Research Literature That Labor Mobility Expands the Income Gap between Urban and Rural Areas}

Based on the theory of neoclassical theory, Liao Xianlang [16] established a general equilibrium economic development model consisting of three commodities. The empirical results show that labor mobility can indeed narrow the income gap between urban and rural areas, but under the conditions of limited labor mobility and the rapid development of urban economy, it is difficult to realize this effect. In addition, as a main method to reduce the cost of labor transfer, the improvement of infrastructure, such as transportation and communication infrastructure, can promote the transfer of rural labor to cities, thereby increasing the marginal labor productivity of the agricultural sector and the income of rural areas, finally narrowing the urban-rural income gap (Liu Chong, Zhou Li'an [17]; Liu Xiaoguang, Zhang Xun, Fang Wenquan [18]; Xie Dongshui [19]) from the perspective of rural land transfer right, through numerical simulation, found that under the premise of considering rural labor transfer costs, there is a positive relationship between the transferability of rural land use rights and rural labor migration, mainly through the promotion of agricultural technology and land property mobility, resulting in a narrowing of urban-rural income gap. Some scholars also believe that the labor force flow has a phased reduction effect on the income gap between urban and rural areas. Li Bin [20] based on the perspective of the life cycle, divided the labor flow into three phases: first is the rural non-agricultural industry employment stage, the second is the period of urban permanent employment, and the third is getting urban household registration by moving from the countryside to the city. The study found that the first and third phases can significantly narrow the income gap between urban and rural areas, and the second phase has an insignificant expansion effect, but the overall impact is still narrowing. The studies of Shao Yihang, Wang Yujuan, and Liu Yanan [21] show that when the proportion of higher education in the flow of labor exceeds half, the mobility of labor force can narrow the income gap between urban and rural areas. Wang Ying [22] uses the CGE model of the three 
sectors of the two regions, through the simulation scheme of five kinds of labor force transfer in different industries and regions which find that the transfer of surplus labor in rural areas will narrow the income gap between urban and rural areas in backward areas.

In summary, domestic and foreign scholars' research on this issue is mainly limited to provincial-level data, and it is not able to refine the impact of labor mobility on urban-rural income gap.

\section{Empirical Research}

\subsection{Definition of Variables and Model Settings}

Due to the lack of data in many cities after 2012, this paper uses the panel data of 272 prefecture-level cities across the country from 2003 to 2012 to study labor mobility and the impact on urban-rural income gap. The data are mainly derived from the Statistical Yearbook of China's Cities and the Statistical Yearbook of China's Urban Construction. Some cities were severely deleted due to missing data. These cities include: Lhasa, Luliang, Bayannaoer, Hezhou, Chongzuo, Sanya, Meishan, Linyi, Shangluo, Dingxi, Weinan, Guyuan, Zhongwei, Chaohu, Shenzhen, and the missing value of a few cities is filled by the statistical yearbook of the province they belong to.

There are three main ways to measure the income gap between urban and rural areas: the first is the Theil index method, followed by the urban and rural Gini coefficient method, and the third is the income ratio method. Taking into account the availability of municipal-level data, this paper uses the income ratio method to measure the urban-rural income gap, that is, the ratio of disposable income of urban residents to the actual net income of rural residents. At present, there is no clear and unified calculation method for the calculation of rural labor mobility. This article uses Lu Ming, Chen Yu (2004), and Chen Guangpu (2014) as examples to use indirect measurement indicators to measure labor mobility, that is, expressed as the proportion of the population's mechanical growth to the total population (\%),Ying Ruiyao and Ma Shaojun (2009) have pointed out that the indicator has a strong correlation with labor flow through path analysis. The absolute value of the correlation coefficient is 0.894 . The population of mechanical growth $=$ the total population at the end of the year - the total population at the end of last year - the total population at the end of last year $\times$ the natural growth rate of the population in this year. The control variables adopted include: the industrial structure. The upgrading and rationalization of the industrial structure will have an impact on the employment structure of the labor force, which will in turn affect the growth of the economy and income, and this paper uses the ratio of the tertiary industry to GDP to describe the industrial structure. The industrialization process is expressed by the proportion of the secondary industry and the tertiary industry in GDP and the level of investment in science and education is measured by using the government's scientific and educational expenditures as a percentage of total financial expenditure. The scale of financial 
development, financial development has a certain threshold effect. For rural residents, due to their own economic level and the number of assets that can be mortgaged, it is difficult for them to enjoy better financial services. On the contrary, urban residents have a better economic level and can provide more collateral assets, so they can accept good financial services to increase their income, which will further widen the income gap between urban and rural areas, and this paper uses the total loans of financial institutions at the end of the year as a proportion of real GDP. The last control variable is social security which is closely related to people's living standards, this paper uses the number of beds owned by each city hospital and hospital.

The benchmark model established in this paper is:

$$
\text { Gap }_{i t}=\alpha \times \text { Laborflow }_{i t}+\beta_{j} \sum_{j} X_{j i t}+\varepsilon_{i t}
$$

Gap $_{i t}$ and Laborflow $_{i t}$ represent the urban-rural income gap and labor flow of city $t$ in period $i, X_{j i t}$ represents the jth control variable of city $t$ in period $i$, and $\varepsilon_{i t}$ is a random error term. In general, for the panel data analysis, it is usually assumed that the random error term obeys the normal distribution, but if the data has some correlation at the tail, or the distribution of the data has spikes or tails, the general regression estimation results will no longer be robust and good, what's more the overall structural characteristics of the data will not be displayed. In order to verify the influence of various explanatory variables on the distribution of the explanatory variables, this paper uses quantile regression for further analysis. The quantile regression has no strict assumptions on the specific distribution of error terms. When the error term does not satisfy the assumption of normal distribution, the regression results can still maintain validity. Compared with the ordinary least squares method, the quantile regression can obtain the regression equations located at different points, and the sensitivity to the outliers of the parameters is reduced, making the results more robust and it is more convenient to explain the overall regression relationship of the explained variables. The quantile regression model is:

$$
Q_{i t}\left(\tau_{j} \mid x_{i t}, \alpha_{i}\right)=x_{i t} \beta\left(\tau_{j}\right)+\alpha_{i}
$$

where $\tau_{j}$ ranges from $(0,1)$ which represent the jth quantile, $Q_{i t}\left(\tau_{j} \mid x_{i t}, \alpha_{i}\right)$ represents the quantile under $\tau_{j}, \beta$ is the coefficient vector of the explanatory variable, $\alpha_{i}$ represents a random effect vector. The quantile regression model for this article is:

$$
\operatorname{Gap}_{\theta i t}=\beta_{\theta i t} X_{i t}+u_{\theta i t}
$$

\subsection{Regression Results and Analysis}

Based on the above analysis, this paper uses OLS and quantile regression analysis methods to empirically examine the effects of labor mobility on urban-rural income gaps. The statistical description of each variable is shown in Table 1 , and the results of OLS and quantile regression are shown in Table 2, Table 3. 


\subsubsection{OLS Regression Results and Analysis}

First, the OLS regression results show that the coefficient of labor mobility variables is negative, indicating that labor mobility has narrowed the urban-rural income gap and is significant at the $1 \%$ level. This is consistent with Lewis's classical dualistic theory, that is, because the labor productivity and wage rate of the non-agricultural sector is higher than that of the agricultural sector, the surplus labor force in the agricultural sector has continuously transferred to non-agricultural sectors with higher marginal productivity, finally, the economy has transformed from binary to one dollar. On the one hand the free flow of labor has increased the income of non-agricultural sectors, and on the other hand it has increased the competition among labor forces in non-agricultural sectors, resulting in a convergence of incomes in both sectors.

Second, the coefficients of industrial structure, investment in science and education, and scale of financial development are positive. They are significant

Table 1. The statistical description of each variable.

\begin{tabular}{|c|c|c|c|c|c|}
\hline Variable & Obs & Mean & Std. Dev. & Min & Max \\
\hline income gap & 2720 & 2.713719 & 0.813141 & 1.296214 & 28.66556 \\
\hline labor flow & 2720 & -5.22079 & 4.128764 & -39.006 & 8.992013 \\
\hline structure & 2720 & 37.01544 & 74.9165 & 8.58 & 3919 \\
\hline industry & 2720 & 0.86555 & 0.750847 & 0.5011 & 39.7137 \\
\hline st & 2720 & 0.19595 & 0.05192 & $7.46 \mathrm{E}-05$ & 0.596484 \\
\hline $\mathrm{Fd}$ & 2720 & 1.764352 & 2.003266 & 0.159023 & 24.98401 \\
\hline welfare & 2720 & 13085.18 & 11794.81 & 865 & 121,319 \\
\hline
\end{tabular}

Table 2. Results of OLS and quantile regression.

\begin{tabular}{|c|c|c|c|c|c|c|}
\hline & \multirow{2}{*}{$\begin{array}{c}\text { The results of OLS } \\
\text { regression } \\
(1)\end{array}$} & \multicolumn{5}{|c|}{ The results of quantile regression } \\
\hline & & (2) & (3) & (4) & (5) & (6) \\
\hline & OLS & QR_10 & QR_25 & QR_50 & QR_75 & QR_90 \\
\hline \multirow{2}{*}{ labor flow } & $-0.0125^{\star * *}$ & $-0.0261^{* * *}$ & $-0.0295^{\star * *}$ & $-0.0301^{* * *}$ & $-0.0331^{\star * *}$ & $-0.0618^{* * *}$ \\
\hline & {$[0.001]$} & {$[0.000]$} & {$[0.000]$} & {$[0.000]$} & {$[0.000]$} & {$[0.000]$} \\
\hline \multirow{2}{*}{ structure } & $0.00563^{* * *}$ & $-0.00351^{\star * *}$ & $0.00287^{* * *}$ & $0.00612^{* * *}$ & $0.0118^{* * *}$ & $0.0118^{\star * *}[0.000]$ \\
\hline & {$[0.002]$} & {$[0.001]$} & {$[0.001]$} & {$[0.000]$} & {$[0.000]$} & $0.0118 \times 0.000]$ \\
\hline \multirow{2}{*}{ industry } & $-0.559^{* * *}$ & $0.378^{* * *}$ & $-0.262^{\star * *}$ & $-0.589^{\star * *}$ & $-1.152^{\star * *}$ & $-1.161^{\star * \star}$ \\
\hline & {$[0.003]$} & {$[0.000]$} & {$[0.003]$} & {$[0.000]$} & {$[0.000]$} & {$[0.000]$} \\
\hline \multirow{2}{*}{ st } & $0.639^{* *}$ & 0.185 & $0.392^{* *}$ & $0.615^{\star * *}$ & $1.150^{* * *}$ & $2.887^{\star * *}$ \\
\hline & {$[0.033]$} & [0.409] & {$[0.042]$} & {$[0.008]$} & {$[0.000]$} & {$[0.000]$} \\
\hline \multirow{2}{*}{$\mathrm{Fd}$} & $0.0271^{\star *}$ & $0.0472^{* * *}$ & $0.0445^{\star * *}$ & $0.0558^{\star * *}$ & $0.0915^{* * *}$ & $0.0992^{* * *}$ \\
\hline & {$[0.013]$} & {$[0.000]$} & {$[0.000]$} & {$[0.000]$} & {$[0.000]$} & {$[0.000]$} \\
\hline \multirow{2}{*}{ welfare } & $-0.00000992^{\star * \star}$ & -0.000000387 & $-0.00000180^{\star *}$ & $-0.00000366^{* * *}$ & $-0.00000867^{\star * *}$ & $-0.00000910^{\star * \star}$ \\
\hline & {$[0.000]$} & [0.699] & {$[0.037]$} & {$[0.000]$} & {$[0.000]$} & {$[0.000]$} \\
\hline \multirow{2}{*}{ _cons } & $2.880^{* * *}$ & $2.145^{\star * *}$ & $2.566^{* * *}$ & $2.566^{* * *}$ & $3.098^{* * *}$ & $3.052^{* * *}$ \\
\hline & {$[0.000]$} & {$[0.000]$} & {$[0.000]$} & {$[0.000]$} & {$[0.000]$} & {$[0.000]$} \\
\hline $\mathrm{N}$ & 2720 & 2720 & 2720 & 2720 & 2720 & 2720 \\
\hline $\mathrm{F}$ & \multicolumn{6}{|c|}{57.23} \\
\hline
\end{tabular}

p-values in brackets. ${ }^{*} \mathrm{p}<0.1,{ }^{* *} \mathrm{p}<0.05,{ }^{* * *} \mathrm{p}<0.01$. 
Table 3. The results of the regression.

\begin{tabular}{|c|c|c|c|c|c|c|}
\hline \multicolumn{7}{|c|}{ The results of the regression } \\
\hline & (1) & (2) & (3) & (4) & (5) & (6) \\
\hline labor flow & $\begin{array}{c}-0.0658797^{\star * *} \\
{[0.000]}\end{array}$ & $\begin{array}{c}-0.0658904^{* * *} \\
{[0.000]}\end{array}$ & $\begin{array}{c}-0.0651507^{\star * *} \\
{[0.000]}\end{array}$ & $\begin{array}{c}-0.0651507^{* * *} \\
{[0.000]}\end{array}$ & $\begin{array}{c}-0.0586729^{* * *} \\
{[0.000]}\end{array}$ & $\begin{array}{c}-0.05415^{* * *} \\
{[0.000]}\end{array}$ \\
\hline structure & & $\begin{array}{c}0.0001294^{* * *} \\
{[0.000]}\end{array}$ & $\begin{array}{c}0.0047129^{* * *} \\
{[0.008]}\end{array}$ & $\begin{array}{c}0.0046743^{* * *} \\
{[0.008]}\end{array}$ & $\begin{array}{c}0.0038365^{* *} \\
{[0.026]}\end{array}$ & $\begin{array}{c}0.004523^{* * *} \\
{[0.009]}\end{array}$ \\
\hline industry & & & $\begin{array}{c}-0.4620749^{* * *} \\
{[0.009]}\end{array}$ & $\begin{array}{c}-0.4578506^{* * *} \\
{[0.010]}\end{array}$ & $\begin{array}{c}-0.3762279^{* *} \\
{[0.028]}\end{array}$ & $\begin{array}{c}-0.4252955^{* *} \\
{[0.013]}\end{array}$ \\
\hline st & & & & $\begin{array}{c}0.4507698^{* * *} \\
{[0.000]}\end{array}$ & $\begin{array}{c}0.4205465^{\star} \\
{[0.077]}\end{array}$ & $\begin{array}{c}0.5260261^{\star *} \\
{[0.029]}\end{array}$ \\
\hline $\mathrm{Fd}$ & & & & & $\begin{array}{c}0.050091^{* * *} \\
{[0.000]}\end{array}$ & $\begin{array}{c}0.054587^{* * *} \\
{[0.000]}\end{array}$ \\
\hline welfare & & & & & & $\begin{array}{c}-6.07 \mathrm{e}-06^{* * *} \\
{[0.000]}\end{array}$ \\
\hline _cons & $\begin{array}{c}2.36137^{* * *} \\
{[0.000]}\end{array}$ & $\begin{array}{c}2.35647^{* * *} \\
{[0.000]}\end{array}$ & $\begin{array}{c}2.593927^{* * *} \\
{[0.000]}\end{array}$ & $\begin{array}{c}2.513822^{* * *} \\
{[0.000]}\end{array}$ & $\begin{array}{c}2.412804^{* * *} \\
{[0.000]}\end{array}$ & $\begin{array}{c}2.509012^{\star * *} \\
{[0.000]}\end{array}$ \\
\hline Under identification test & $\begin{array}{l}382.110 \\
{[0.000]}\end{array}$ & $\begin{array}{l}382.209 \\
{[0.000]}\end{array}$ & $\begin{array}{l}384.896 \\
{[0.000]}\end{array}$ & $\begin{array}{l}368.460 \\
{[0.000]}\end{array}$ & $\begin{array}{l}352.151 \\
{[0.000]}\end{array}$ & $\begin{array}{l}348.372 \\
{[0.000]}\end{array}$ \\
\hline Weak identification test & $\begin{array}{l}296.430 \\
{[0.000]}\end{array}$ & $\begin{array}{l}296.255 \\
{[0.000]}\end{array}$ & $\begin{array}{l}295.860 \\
{[0.000]}\end{array}$ & $\begin{array}{l}275.365 \\
{[0.000]}\end{array}$ & $\begin{array}{l}261.293 \\
{[0.000]}\end{array}$ & $\begin{array}{l}252.433 \\
{[0.000]}\end{array}$ \\
\hline Hansen J statistic & $\begin{array}{c}0.174 \\
{[0.6770]}\end{array}$ & $\begin{array}{c}0.172 \\
{[0.6785]}\end{array}$ & $\begin{array}{c}0.264 \\
{[0.6076]}\end{array}$ & $\begin{array}{c}0.265 \\
{[0.6067]}\end{array}$ & $\begin{array}{c}0.125 \\
{[0.7238]}\end{array}$ & $\begin{array}{c}0.064 \\
{[0.7997]}\end{array}$ \\
\hline $\mathrm{N}$ & 2720 & 2720 & 2720 & 2720 & 2720 & 2720 \\
\hline
\end{tabular}

p-values in brackets. ${ }^{*} \mathrm{p}<0.1,{ }^{* *} \mathrm{p}<0.05,{ }^{* *} \mathrm{p}<0.01$.

at the levels of $1 \%, 5 \%$, and $5 \%$, respectively. This shows that the upgrading of the industrial structure, the increase in the level of scientific education investment, and the expansion of the financial development scale will widen the income gap between urban and rural areas. From the perspective of industrial structure, due to the typical urban-rural dual industrial structure in China, the gap between human capital in urban and rural areas has not been improved in the process of optimizing and upgrading the industrial structure. In addition, the industrial transfer and labor transfer in developing countries are not synchronized, which will lead to an increase in the gap between the production efficiency of various departments and further increase the income gap between urban and rural areas. From the perspective of science and education investment, the increase in the investment in science and education can promote the improvement of the level of human capital, and thus promote the development of the economy in theory. However, our country's long-standing science, education and finance policies all have obvious "urban bias", which makes educational resources more inclined to urban areas, rural education infrastructure is lagging behind, weak teacher force and the unequal distribution of public funding for science and education in urban and rural areas have exacerbated inequality between urban and rural incomes, it is not implemented the attribute as a public product. From the perspective of the scale of financial development, China's financial resources are mainly concentrated in urban areas, and the financial development in rural areas is in a restrained state compared with urban areas. On 
the other hand, the urban residents' ability to use funds is significantly higher than that of rural residents. At the same time, they have the ability to take on and pay for the cost of enjoying financial services, which in turn leads to higher capital gains. This can allow more effective allocation of funds, resulting the rich have been getting richer and the poor poorer.

Finally, the coefficients of industrialization and social security level variables are negative, and both are significant at the $1 \%$ level. This shows that the progress of industrialization and the improvement of social welfare will narrow the income gap between urban and rural areas. From the perspective of industrialization, the development of industrialization has increased the specialization of the division of labor, and the specialized division of labor has further increased the ability to cooperate between workers and workers and between workers and enterprises. At the same time, industrialization has created more non-agricultural jobs for farmers, broadened the employment channels for farmers, increased farmers' non-agricultural income, and finally promoted economic development. From the point of view of social security, the government's social security compensates for the fairness that market mechanisms ignore when pursuing efficiency goals. Allocating social welfare to individual residents can enable residents to accumulate disposable income. On the other hand, the social security system tends to favor low-income groups, such as rural residents, to balance the income of various strata, thus maintaining the overall stability and harmony of society.

\subsubsection{Quantile Regression Results and Analysis}

This paper returns the urban-rural income gap from the 5 points of $10 \%, 25 \%$, $50 \%, 75 \%$, and $90 \%$, and columns (1) to (6) in Table 1 report the regression results of the explanatory variable and each control variable at different quantile points. The impact of labor mobility variables on urban-rural income gap at all locator sites is significant, and both are negative. With the increase of quantile sites, the impact of labor mobility on urban-rural income gaps is also increasing. Whereas, from $75 \%$ points to $90 \%$ points, labor mobility has the greatest reduction in the urban-rural income gap. The income gap between urban and rural areas in high-ranking cities is inferior to that in low-lying locations, and the impact of labor mobility on prefecture-level cities with large urban-rural income gap is greater than that in urban-rural areas with small income gaps. Combined with the research sample of this paper, cities with large urban-rural income gaps have larger labor flows, while those with smaller urban-rural income gaps have smaller labor flows.

Second, the symbolic changes occurred when the industrial structure and industrialization level jumped from the $10 \%$ quantile point to the $25 \%$ quantile point. At the 10th percentile, the coefficient of the industrial structure variable is negative, and the coefficient of the industrialization level variable is positive. At the $25 \%$ quintile, the coefficient of the industrial structure variable is positive, and the coefficient of the industrialization level variable is negative. It shows that 
the industrial structure variable has a positive effect on the areas with better income disparity, that is, with the upgrading of the industrial structure, the income gap between urban and rural areas is continuously shrinking. On the contrary, the areas with large differences in income disparity have a reverse effect. Combined with the sample of this paper, in cities with a small income gap between urban and rural areas, the level of industrialization is generally low, and the proportion of resource-based industries is relatively large and this extensive industrial development model leads to the depletion of resources and cannot create more jobs which have exacerbated the tension between urban and rural income. On the contrary, in areas with high income disparity between urban and rural areas, high-end heavy industries are mainly based on equipment manufacturing. Compared with traditional industrial models, high-end heavy industries can absorb more rural labor and increase the income of rural residents. The level of investment in science and education and the scale of financial development are consistent with the regression results of OLS which have a negative impact on the urban-rural income gap. Among them, the scale of financial development showed a fluctuating effect on the income gap, which dropped from 0.0472 points at $10 \%$ points to 0.0445 points at $25 \%$ points, and then increased to 0.0558 points at the $50 \%$ points. The increase in the investment in science and education from a low quintile to a high quintile shows a large increase. Compared with the rate of return of 0.185 for a $10 \%$ divergence point, the $90 \%$ quintile rises to 2.887 , indicating that it has a greater impact on areas with large income gaps. With the increase of quantile points, the Significantness and the impact of Social Security are improving. However, the overall effect of social security on the reduction of urban-rural income gap is very small. The coefficient at the $90 \%$ quintile is only 0.0000091 . This is mainly related to the incompleteness of China's social security system. At present, China has not yet introduced a legal regulation on social security, mainly relying on orders, documents, administrative regulations, and other documents. For example, in many places, due to the imperfect supervision system, some officials will use their own rights to allocate these subsistence allowances, unemployment benefits, etc., ultimately resulting in the inability of these guarantees to be paid to those who need them most, thereby hindering the true role of the social security system.

\subsubsection{Endogenous Treatment}

Considering that the variable of labor mobility will not only affect the urban-rural income gap, but also the higher income level and more employment opportunities in cities will attract large numbers of rural laborers to migrate to cities and towns, that is, there may be a causal relationship between income gap between urban and rural areas and labor mobility, so it has endogenous problems. Serious endogenous problems will lead to biased and non-uniformity of the least squares estimation, in this paper, the lagged one and lagged two phases of labor flow are used as instrumental variables. Two-stage least-squares regression is used to solve the endogeneity problem by adding control variables one by 
one. The general rule for selecting instrumental variables is that instrumental variables are highly correlated with endogenous variables, and are not related to the explanatory variable and random error term. The adoption of lag phase 1 and lag phase 2 as the instrumental variables is mainly due to the fact that the lag phase 1 and lag phase 2 labor flows have a strong correlation with the current labor flow and are not related to the urban-rural income gap of the explained variables. Secondly, the lag period variable as a tool variable is also a commonly used method to deal with endogenous problems. For example, Chen Guangpu (2014), Lu Ming et al. (2004), Ying Ruiyao et al. (2011) adopted the lag time of variables to solve endogenous problems. At the same time, in order to ensure the effectiveness of the selected instrumental variables, this paper conducts over-identification tests, under-identification tests, and weak-identification tests on the lagged and late phases of labor flow variables. The results of the regression are shown in Table 2.

From the results in Table 2, it can be seen that compared with the results in Table 1, the estimation coefficient of the labor mobility variable has been improved to a greater extent, which indicates that the ordinary least squares estimation is biased due to the endogeneity of the labor flow variable, and thus underestimates the effect of labor mobility on the reduction of urban-rural income gap. And other coefficients are also significant, indicating that the two tool variables selected in this paper can effectively deal with the endogeneity problems existing in the model, make the regression results more reasonable, and have stronger explanatory power on the issues studied. At the same time, Table 2 also lists the test results for instrumental variables, where under identification test and Weak identification test are both reject the under-identification of instrumental variables and the weakly identified null hypothesis at the $1 \%$ significance level. On the other hand, the value of Hansen J statistic indicates that there is no problem with the excessive selection of instrumental variables in this paper, which once again verifies the rationality of the instrumental variables.

\section{Research Conclusions and Policy Recommendations}

Based on the urban-rural dual economic theory and income hypothesis, this paper empirically analyzes the impact of labor mobility on urban-rural income gap using panel data from 272 prefecture-level cities from 2003 to 2012 . The results show that the impact of labor mobility on urban-rural income gap is also affected by such factors as industrial structure, industrialization level, science and education investment level, financial development scale and social security strength. In general, the absolute value of the coefficient of labor flow variables is small compared with other control variables, which shows that the impact of labor mobility on urban-rural income gap is relatively small, which is mainly related to the current labor flow and has not reached a reasonable scale. At different quantile points, as the scale of labor mobility increases, the income gap between urban and rural areas continues to decrease, and as the quantile points 
rise, this reduction effect will also increase. The income gap between urban and rural areas in high-ranking cities is inferior to that in low-lying locations, and the impact of labor mobility on prefecture-level cities with large urban-rural income gap is greater than that in urban-rural areas with small income gaps. The symbolic changes have taken place in the industrial structure and industrialization level when they jumped from the $10 \%$ quantile point to the $25 \%$ quantile point. The investment in science and education, the scale of financial development, and the impact of social security have not changed at different points.

Based on the above empirical research results, this paper believes that efforts should be made to reduce the urban-rural income gap from the following aspects: First, in order to realize the effect of labor mobility on the reduction of urban-rural income gap, it is necessary to ensure the barrier-free flow of labor and further develop the labor market. We will deepen the integration of labor and employment systems in urban and rural areas in China, eliminate urban restrictions on the transfer of rural labor, and break policy barriers such as the household registration system and the urban social security system that result in low labor mobility and unstable flow direction. Accelerating the reform of China's household registration and employment system, can provide rural laborers equal opportunity and treatment, promote the transition from rural labor to non-agricultural and permanent transfer, and also reduce the employment costs and thresholds of rural laborers entering the cities. On the other hand, from the perspective of employment structure, industrialization level, science and education investment level, financial development scale, and social welfare protection, we should pay attention to the human capital of the mobile labor force in the process of optimizing and upgrading the industrial structure; The government should reduce the "urban bias" in science and education investment and provide fair and equal opportunities to the rural labor force; It also should improve rural financial service quality and environment and innovate rural financial products so that urban financial resources can serve the rural economy more reasonably and effectively. The government is supposed to further promote the development of industrialization, create more non-agricultural jobs for farmers, broaden the employment channels for farmers, and increase the non-agricultural income of farmers. Deepening the reform of China's social welfare system and realizing the equal distribution of social welfare between urban and rural areas can truly benefit the residents and provide guarantees for narrowing the urban-rural income gap.

\section{Conflicts of Interest}

The authors declare no conflicts of interest regarding the publication of this paper.

\section{References}

[1] Lin, J.Y., Wang, G. and Zhao, Y. (2004) Regional Inequality and Labor Transfers in China. Economic Development and Cultural Change, 52, 587-603. 
https://doi.org/10.1086/421481

[2] Chan, K.W. and Buckingham, W. (2008) Is China Abolishing the HuKou System? The China Quarterly, 2, 156-179.

[3] Zhang, Y. and Wang, H. (2011) The Household Registration Discrimination and Regional Discrimination in Urban Labor Market: A Study Based on Population Census Data. Management World, 7, 42-51.

[4] Yu, X.H. and Chen, X.J. (2012) The Household Registration Segmentation Effect and Changes in China's Labor Market: An Empirical Study from the Perspective of Wage Differences and Opportunity Differences. Economic Research Journal, 12, 97-110.

[5] Zhang, L. and Li, S. (2014) The Household Registration Discrimination of Wages Income in China's Labor Market. Management World, 11, 35-46.

[6] Fan, S.D. (2011) Research on the Kuznets Effect of Labor Flow and Income Disparity in China. Economic Review, 4, 44-53.

[7] Zhai, Y.F. and Zhan, W.M. (2016) Selective Transfer, Transfer Costs and Changes in China's Urban-Rural Income Gap. China Population, Resources and Environment, 8, 125-134.

[8] Cai, W. and Chen, G.H. (2013) Heterogeneous Human Capital Spillover, Labor Mobility and Urban-Rural Income Gap. Journal of Yunnan University of Finance and Economics, 6, 24-32.

[9] Cai, W., Wu, G.B. and Zhu, X. (2013) The Influence of the Externality of Spatial Agglomeration and Rural Labor Mobility on the Income Gap. Industrial Economics Research, 2, 21-30.

[10] Zheng, J.H. and Gao, Y.Y. (2009) From Labor Flow to Regional Industry Transfer: An Analysis of the Evolutionary Mechanism of Jiangsu's Double Dualistic Economic Structure. Journal of Audit \& Economics, 4, 71-84.

[11] Chen, J.J. (2009) Factor Flow, Industrial Transfer and Regional Economic Integration. Zhejiang University Press, Hangzhou, 36-51.

[12] Cai, W. and Chen, W.Y. (2012) Urban-Rural Income Gap and Industrial Agglomeration Based on Spatial Perspective. East China Economic Management, 5, 32-36.

[13] Liu, J., Wang, J.X. and Yang, H.C. (2015) The Impact of Industrial Clusters on the Income Gap between Urban and Rural Residents-An Empirical Study Based on Chinese Provincial Panel Data. Rural Economy, 5, 44-49.

[14] Deng, X. (2011) Fiscal Expenditure Size, Structure and Income Inequalities in Urban and Rural Areas. Economic Review, 4, 63-69.

[15] Ge, L., Tao, X.M. and Wang, H. (2015) Local Fiscal Finance, Urbanization, and Urban-Rural Income Gap. China Population, Resources and Environment, 9, 93-99.

[16] Liao, X. (2012) Research on Rural Labor Mobility and Urban-Rural Income Gap in China. Population \& Economics, 6, 46-52.

[17] Liu, C. and Zhou, L. (2014) Expressway Construction and Regional Economic Development: Evidence from China's County Level. Economic Science, 2, 55-67.

[18] Liu, X., Zhang, X. and Fang, W. (2015) Urban and Rural Income Distribution Effects of Infrastructure: Based on the View of Labor Transfer. The Journal of World Economy, 3, 145-170.

[19] Xie, D. (2014) Agricultural Land Transfer Rights, Labor Migration and Urban-Rural Income Gap. China Economic Studies, 1, 49-59.

[20] Li, B. (2013) The Impact of Labor Mobility on Urban-Rural Income Gap: Based on 
H. Li

Life Cycle Perspective. China Population, Resources and Environment, 11, 102-107.

[21] Shao, Y., Wang, Y. and Liu, Y. (2016) The Evolution of Labor Mobility and Income Gap: Based on the Theory and Evidence of Chinese Cities. Economist, 1, 33-41.

[22] Wang, Y. (2015) The Impact of Rural Labor Transfer on China's Urban-Rural Income Gap: An Analysis Based on CGE Model. Chinese Review of Financial Studies, $5,82-92+125$. 